\title{
Collaborative effects of bystander-initiated cardiopulmonary resuscitation and prehospital advanced cardiac life support by physicians on survival of out-of-hospital cardiac arrest: a nationwide population-based observational study
}

Hideo Yasunaga ${ }^{1 *}$, Hiromasa Horiguchi ${ }^{1}$, Seizan Tanabe ${ }^{2}$, Manabu Akahane $^{3}$, Toshio Ogawa ${ }^{3}$, Soichi Koike ${ }^{4}$, Tomoaki Imamura ${ }^{3}$

\begin{abstract}
Introduction: There are inconsistent data about the effectiveness of prehospital physician-staffed advanced cardiac life support (ACLS) on the outcomes of out-of-hospital cardiac arrest (OHCA). Furthermore, the relative importance of bystander-initiated cardiopulmonary resuscitation (BCPR) and ACLS and the effectiveness of their combination have not been clearly demonstrated.

Methods: Using a prospective, nationwide, population-based registry of all OHCA patients in Japan, we enrolled 95,072 patients whose arrests were witnessed by bystanders and 23,127 patients witnessed by emergency medical service providers between 2005 and 2007. We divided the bystander-witnessed arrest patients into Group A (ACLS by emergency life-saving technicians without BCPR), Group B (ACLS by emergency life-saving technicians with $B C P R$ ), Group C (ACLS by physicians without BCPR) and Group D (ACLS by physicians with BCPR). The outcome data included 1-month survival and neurological outcomes determined by the cerebral performance category.

Results: Among the 95,072 bystander-witnessed arrest patients, 7,722 (8.1\%) were alive at 1 month, including 2,754 (2.9\%) with good performance and 3,171 (3.3\%) with vegetative status or worse. BCPR occurred in $42 \%$ of bystander-witnessed arrests. In comparison with Group A, the rates of good-performance survival were significantly higher in Group B (odds ratio (OR), 2.23; 95\% confidence interval, 2.05 to 2.42; $P<0.01$ ) and Group D (OR, 2.80; 95\% confidence interval, 2.28 to 3.43; $P<0.01$ ), while no significant difference was seen for Group C (OR, 1.18; 95\% confidence interval, 0.86 to $1.61 ; P=0.32$ ). The occurrence of vegetative status or worse at 1 month was highest in Group C (OR, 1.92; 95\% confidence interval, 1.55 to $2.37 ; P<0.01)$.

Conclusions: In this registry-based study, BCPR significantly improved the survival of OHCA with good cerebral outcome. The groups with BCPR and ACLS by physicians had the best outcomes. However, receiving ACLS by physicians without preceding BCPR significantly increased the number of patients with neurologically unfavorable outcomes.
\end{abstract}

\footnotetext{
* Correspondence: yasunagah-jyo@h.u-tokyo.ac.jp

'Department of Health Management and Policy, Graduate School of Medicine, The University of Tokyo, 7-3-1 Hongo, Bunkyo-ku, Tokyo 113-8655, Japan

Full list of author information is available at the end of the article
} 


\section{Introduction}

Successful rescue of patients with cardiac arrest outside the hospital setting is a long-term public health issue in most jurisdictions in the majority of countries [1,2]. Reported out-of-hospital cardiac arrest (OHCA) survival rates vary widely [2-8], and this variation can be attributed, in part, to differences among countries in the chain of survival, as described by the American Heart Association [9]. Ideally, communities and emergency medical service (EMS) providers should optimize the following four links: rapid access through an emergency telephone system; early bystander-initiated cardiopulmonary resuscitation (BCPR) [10]; early defibrillation with an automated external defibrillator [11]; and advanced cardiac life support (ACLS) $[12,13]$.

Numerous studies have elucidated the independent effects of BCPR coupled with use of an automated external defibrillator [11]. On the other hand, the extent to which prehospital ACLS can improve patient survival remains somewhat controversial $[7,10,12,13]$, even more than 40 years after Pantridge and Geddes introduced the concept of providing ACLS to OHCA patients through mobile intensive care vehicles [1]. The issue of who provides the prehospital ACLS is considered one of the factors affecting outcomes after OHCA. Several studies have assessed the effects of physician-manned ACLS [12,13], but the studies were conducted in limited geographic areas. Furthermore, the relative importance of BCPR and ACLS and the effectiveness of their combination on the survival rate of patients and their subsequent well-being have not been clearly demonstrated.

The aims of the present study were to analyze the collaborative effects of BCPR and prehospital ACLS with or without physicians on the health outcomes of OHCA patients, in terms of their overall survival and cerebral performance at 1 month.

\section{Materials and methods}

\section{Emergency medical service in Japan}

In Japan, the fire defense headquarters of local governments - which comprised 807 fire stations with dispatch centers as of 2007 - provide the standardized prehospital EMS. The Fire and Disaster Management Agency of Japan (FDMA) supervises the EMS system throughout the nation. Generally, an ambulance crew is organized with three EMS staff members in a local center, including at least one emergency life-saving technician (ELST) who has undergone extensive training for providing prehospital EMS $[11,14]$. ELSTs perform cardiopulmonary resuscitation (CPR) according to the Japanese CPR guidelines, which are based on the guidelines of the American Heart Association and the International Liaison Committee on Resuscitation $[15,16]$. ELSTs provide prehospital EMS procedures that are limited to use of a semiautomated external defibrillator, insertion of an adjunct airway (esophageal obturator airway or laryngeal mask airway), cannulation of a peripheral intravenous line and infusion of lactate Ringer solution and epinephrine. Only specially trained ELSTs are permitted to insert tracheal tubes [14].

The Japanese EMS system is one-tiered. Several regions have their own physician-staffed EMS systems [14,17]. On receipt of an emergency call to a dispatch center in such regions, the EMS personnel request mobilization of a physician-staffed ambulance from an emergency medical center if the patient is suspected of OHCA [18]. Physicianmanned ambulances, although increasing in number, are not yet widespread in Japan. As of April 2009, there were approximately 4,000 hospitals with an emergency room and 218 emergency and critical care centers in all 47 prefectures in Japan. Eighty-six of the 218 centers organized physician-staffed prehospital ACLS systems [19]. A previous questionnaire survey showed that 27 out of 48 physician-staffed ambulance systems worked 24 hours a day while the other 21 systems only worked during the daytime in 2006 [18]. In physician-manned ambulances, prehospital physicians can carry out any emergency treatment according to their diagnoses and judgments, and can select many treatment options including use of a semiautomated external defibrillator, tracheal tube insertion, central venous catheterization, and infusion of catecholamines, lidocaine, atropine, anesthetic drugs and thrombolytic agents. In-hospital treatment after return of spontaneous circulation varies widely between hospitals. In particular, hospitals with physician ACLS typically provide more optimal post-return of spontaneous circulation treatments, including therapeutic hypothermia and percutaneous coronary intervention.

\section{Data source}

In January 2005, the FDMA launched a prospective, nationwide, population-based, observational study involving all OHCA patients in Japan [11]. The EMS staff in each center recorded the data of OHCA patients using an Utstein-style form [18] in cooperation with the physicians in charge of the patients. The anonymous data were sent electronically to the FDMA database server. The database included the following data: sex; age; cause of arrest (cardiac or noncardiac origin); bystander's witness status; presence of BCPR; times of collapse, emergency call, vehicle arrival at the scene, initiation of CPR and first shock; initial rhythms, including ventricular fibrillation (VF), pulseless electrical activity and asystole; information on the EMS crew (physician-staffed or not); 1-month survival; and neurological outcome 1 month after cardiac arrest, defined as the GlasgowPittsburgh cerebral performance category (CPC) $[9,20]$. 
The physician in charge made a diagnosis of the cause of arrest in collaboration with the EMS staff.

The FDMA offered all of the anonymous data to our research group. The present study was approved by the Institutional Review Board of Nara Medical University.

\section{Subjects}

In the present study, we enrolled all OHCA patients who were witnessed by laypeople or EMS providers, who received or did not receive $B C P R$, who underwent prehospital ACLS by ELSTs or physicians and who were transported to medical facilities from 1 January 2005 to 31 December 2007. While a witnessed arrest status is one of the strong prognostic factors for survival of OHCA, an unwitnessed arrest is associated with little possibility of survival [9]. In the present study, patients were excluded from the analysis if their cardiac arrest was not witnessed or if the witness status was not documented.

We divided the bystander-witnessed OHCA patients into the following four groups: patients who did not undergo BCPR and were treated with prehospital ACLS by ELSTs (Group A: ACLS by ELSTs without BCPR); patients who underwent BCPR and were treated with prehospital ACLS by ELSTs (Group B: ACLS by ELSTs with BCPR); patients who did not undergo BCPR and were treated with prehospital ACLS by physicians (Group C: ACLS by physicians without BCPR); and patients who underwent BCPR and were treated with prehospital ACLS by physicians (Group D: ACLS by physicians with BCPR).

For the EMS provider-witnessed OHCA patients, we divided the population into two groups treated with prehospital ACLS by ELSTs or by physicians.

\section{Endpoints}

Outcome data included 1-month survival and neurological status 1 month after the event, defined by the GlasgowPittsburgh CPC: good performance, CPC1; moderate disability, CPC2; severe cerebral disability, CPC3; vegetative state, CPC4; or brain death, CPC5. In the database, a de facto brain-death case was considered still alive if the patient had not been diagnosed with the standard diagnostic criteria for brain death but was coded as CPC5.

\section{Analyses}

We performed univariate comparisons of the patient characteristics and outcome variables using chi-square tests and analysis of variance as appropriate. Logistic regression analyses were performed to model the concurrent effects of BCPR, ACLS and other factors on the outcomes. The threshold for significance was $P<0.05$. All statistical analyses were conducted using PASW Statistics version 18.0 (SPSS Inc., Chicago, IL, USA).

\section{Results}

During the study period, we identified 95,072 bystanderwitnessed OHCA patients $(29,215$ in $2005,31,849$ in 2006 and 34,008 in 2007) and 23,127 EMS providerwitnessed OHCA patients $(7,554$ in 2005, 7,717 in 2006 and 7,856 in 2007).

Table 1 presents demographic data of the bystander-witnessed OHCA patients. Overall, 39,993 patients (42.1\%) received BCPR and 3,513 patients (3.7\%) received ACLS by physicians. The median times from collapse to CPR were 2 minutes in Group B and Group D with BCPR, and 10 minutes in Group A and Group C without BCPR.

Table 2 presents the 1-month survival rates and CPC rates of all the bystander-witnessed OHCA patients and those with initial VF of cardiac origin. Among the 95,072 bystander-witnessed OHCA patients, the 1-month survival was $8.1 \%$, including $2.9 \%$ with good performance and $3.3 \%$ with vegetative status or worse. The rate of patients with vegetative status or worse among all survivors was $41.4 \%$ $(3,171$ out of 7,722$)$. Significant differences were found in the 1-month survival and good cerebral performance between Group A and Group B $(P<0.01)$, between Group $\mathrm{C}$ and Group D $(P<0.01)$ and between Group B and Group D $(P<0.01)$. In comparisons of Group A and Group $C$, significant increases were found in the 1-month survival $(6.7 \%$ vs. $11.6 \%, P<0.01)$ and vegetative status or worse $(3.1 \%$ vs. $6.1 \%, P<0.01)$, while the difference in good performance was not significant $(1.9 \%$ vs. $2.7 \%, P=$ 0.41 ). Among the 11,970 bystander-witnessed OHCA patients with initial VF of cardiac origin, the 1-month survival was $24.3 \%$, including $12.0 \%$ with good performance and $6.4 \%$ with vegetative status or worse. Differences among the groups were similar to all the bystanderwitnessed OHCA patients, and the rate of vegetative status or worse was highest in Group C (11.8\%).

Table 3 presents the results of logistic regression analyses for the 1-month outcomes of all the bystanderwitnessed OHCA patients and those with initial VF of cardiac origin. Among all of the bystander-witnessed OHCA patients, lower rates of overall survival and neurologically good-performance survival were significantly associated with older age and longer call-response interval. The rate of good-performance survival was significantly higher in Group B than in Group A (odds ratio (OR), 2.23; $P<0.001$ ), but did not differ significantly between Group A and Group C (OR, 1.18; $P=0.317$ ). Group D showed the highest good-performance survival $(\mathrm{OR}, 2.80 ; P<0.001)$. The occurrence of vegetative status or worse was highest in Group C (OR, 1.87; $P<0.001)$. Similar trends were seen in patients with initial VF of cardiac origin, among whom Group D showed significantly improved good-performance survival (OR, 2.06; $P<0.001$ ) while Group $C$ showed a significantly higher 
Table 1 Baseline characteristics of patients whose arrests were witnessed by bystanders

\begin{tabular}{|c|c|c|c|c|c|c|c|c|c|c|}
\hline & \multicolumn{2}{|c|}{ All $(n=95,072)$} & \multicolumn{2}{|l|}{$\begin{array}{c}\text { Group A } \\
(n=53,482)\end{array}$} & \multicolumn{2}{|c|}{$\begin{array}{c}\text { Group B } \\
(n=38,077)\end{array}$} & \multicolumn{2}{|l|}{$\begin{array}{c}\text { Group C } \\
(n=1,597)\end{array}$} & \multicolumn{2}{|l|}{$\begin{array}{l}\text { Group D } \\
(n=1,916)\end{array}$} \\
\hline & $n$ & $\%$ & $n$ & $\%$ & $n$ & $\%$ & $n$ & $\%$ & $n$ & $\%$ \\
\hline Sex (males) & 58,745 & 61.8 & 34,297 & 64.1 & 22,210 & 58.3 & 1,058 & 66.2 & 1,180 & 61.6 \\
\hline Age (years) & $71.6 \pm 17.8(75)$ & & $70.9 \pm 17.4(75)$ & & $72.9 \pm 18.1(77)$ & & $65.9 \pm 20.1(71)$ & & $69.2 \pm 18.8(73)$ & \\
\hline \multicolumn{11}{|l|}{ Causes of arrest } \\
\hline Cardiac origin & 52,830 & 55.6 & 28,825 & 53.9 & 21,967 & 57.7 & 835 & 52.3 & 1,203 & 62.8 \\
\hline Noncardiac origin & 42,242 & 44.4 & 24,657 & 46.1 & 16,110 & 42.3 & 762 & 47.7 & 713 & 37.2 \\
\hline \multicolumn{11}{|l|}{ Initial rhythm } \\
\hline $\begin{array}{l}\text { Ventricular } \\
\text { fibrillation }\end{array}$ & 13,705 & 14.4 & 6,744 & 12.6 & 6,292 & 16.5 & 245 & 15.3 & 424 & 22.1 \\
\hline $\begin{array}{l}\text { Pulseless electrical } \\
\text { activity }\end{array}$ & 31,141 & 32.8 & 18,580 & 34.7 & 11,361 & 29.8 & 573 & 35.9 & 627 & 32.7 \\
\hline Asystole & 47,328 & 49.8 & 27,129 & 50.7 & 18,724 & 49.2 & 712 & 44.6 & 763 & 39.8 \\
\hline Others & 2,898 & 3.0 & 1,029 & 1.9 & 1,700 & 4.5 & 67 & 4.2 & 102 & 5.3 \\
\hline $\begin{array}{l}\text { Collapse to initiation of } \\
\text { CPR (minutes) }\end{array}$ & $8.9 \pm 10.0(7.0)$ & & $12.5 \pm 10.2(10.0)$ & & $4.1 \pm 7.2(2.0)$ & & $\begin{array}{l}13.0 \pm 11.6 \\
(10.0)\end{array}$ & & $3.0 \pm 6.1(2.0)$ & \\
\hline $\begin{array}{l}\text { Collapse to EMS } \\
\text { response (minutes) }\end{array}$ & $11.3 \pm 9.7(9.0)$ & & $10.9 \pm 9.9(9.0)$ & & $11.7 \pm 9.7(10.0)$ & & $11.0 \pm 10.8(8.0)$ & & $12.4 \pm 11.6(9.0)$ & \\
\hline $\begin{array}{l}\text { Collapse to first shock } \\
\text { (minutes) }\end{array}$ & $13.1 \pm 6.2(12.0)$ & & $12.8 \pm 6.4(12.0)$ & & $13.4 \pm 6.0(12.0)$ & & $12.4 \pm 6.2(11.0)$ & & $13.1 \pm 6.4(12.0)$ & \\
\hline $\begin{array}{l}\text { Call to EMS response } \\
\text { (minutes) }\end{array}$ & $7.3 \pm 4.5(6.0)$ & & $7.0 \pm 4.4(6.0)$ & & $7.7 \pm 4.5(7.0)$ & & $7.2 \pm 5.5(6.0)$ & & $7.2 \pm 4.2(6.0)$ & \\
\hline
\end{tabular}

occurrence of vegetative status or worse (OR, 1.56; $P=0.016)$.

Table 4 presents the demographics and outcomes of patients whose arrests were witnessed by EMS providers, and Table 5 presents logistic regression analyses for these patients. The group treated with ACLS by physicians showed higher overall survival (OR, 1.27; $P=0.013)$ and good-performance survival (OR, 1.47; $P<0.001$ ), while the occurrence of vegetative status or worse did not differ between the two groups (OR, 0.92; $P=0.646)$.

Table 2 One-month outcomes of bystander-witnessed OHCAs and those with initial VF of cardiac origin

\begin{tabular}{|c|c|c|c|c|c|c|c|c|c|c|}
\hline & \multicolumn{2}{|c|}{ All } & \multicolumn{2}{|c|}{ Group A } & \multicolumn{2}{|c|}{ Group B } & \multicolumn{2}{|c|}{ Group C } & \multicolumn{2}{|c|}{ Group D } \\
\hline & $n$ & $\%$ & $n$ & $\%$ & $n$ & $\%$ & $n$ & $\%$ & $n$ & $\%$ \\
\hline All bystander-witnessed OHCAs & 95,072 & & 53,482 & & 38,077 & & 1,597 & & 1,916 & \\
\hline 1-month survival & 7,722 & 8.1 & 3,608 & 6.7 & 3,642 & 9.6 & 185 & 11.6 & 287 & 15.0 \\
\hline \multicolumn{11}{|l|}{$\mathrm{CPC}$ at 1 month } \\
\hline Good performance & 2,754 & 2.9 & 1,026 & 1.9 & 1,562 & 4.1 & 43 & 2.7 & 123 & 6.4 \\
\hline Moderate disability & 659 & 0.7 & 317 & 0.6 & 294 & 0.8 & 17 & 1.1 & 31 & 1.6 \\
\hline Severe cerebral disability & 1,117 & 1.2 & 560 & 1.0 & 489 & 1.3 & 28 & 1.8 & 40 & 2.1 \\
\hline Vegetative status or worse & 3,171 & 3.3 & 1,694 & 3.2 & 1289 & 3.4 & 97 & 6.1 & 91 & 4.7 \\
\hline Bystander-witnessed OHCAs with initial VF of cardiac origin & 11,970 & & 5,840 & & 5,518 & & 229 & & 383 & \\
\hline 1-month survival & 2,903 & 24.3 & 1,247 & 21.4 & 1,443 & 26.2 & 74 & 32.3 & 139 & 36.3 \\
\hline \multicolumn{11}{|l|}{$\mathrm{CPC}$ at 1 month } \\
\hline Good performance & 1,436 & 12.0 & 524 & 9.0 & 810 & 14.7 & 27 & 11.8 & 75 & 19.6 \\
\hline Moderate disability & 297 & 2.5 & 137 & 2.3 & 130 & 2.4 & 10 & 4.4 & 20 & 5.2 \\
\hline Severe cerebral disability & 395 & 3.3 & 197 & 3.4 & 173 & 3.1 & 10 & 4.4 & 15 & 3.9 \\
\hline Vegetative status or worse & 771 & 6.4 & 387 & 6.6 & 329 & 6.0 & 27 & 11.8 & 28 & 7.3 \\
\hline
\end{tabular}

One-month outcomes of all the bystander-witnessed out-of-hospital cardiac arrests (OHCAs) $(n=95,072)$ and those with initial ventricular fibrillation (VF) of cardiac origin $(n=11,970)$. Group A, advanced cardiac life support (ACLS) by emergency life-saving technicians (ELSTs) without bystander-initiated cardiopulmonary resuscitation (BCPR); Group B, ACLS by ELSTs with BCPR; Group C, ACLS by physicians without BCPR; Group D, ACLS by physicians with BCPR. $C P C$, cerebral performance category. 
Table 3 Logistic regression analyses for 1-month outcomes for bystander-witnessed OHCAs and those with initial cardiac VF

\begin{tabular}{|c|c|c|c|c|c|c|c|c|c|}
\hline & \multicolumn{3}{|c|}{ 1-month survival } & \multicolumn{3}{|c|}{$\begin{array}{c}\text { Good performance at } 1 \\
\text { month }\end{array}$} & \multicolumn{3}{|c|}{$\begin{array}{l}\text { Vegetative status or de } \\
\text { facto brain death at } 1 \\
\text { month }\end{array}$} \\
\hline & $\overline{\mathrm{OR}}$ & $95 \% \mathrm{Cl}$ & $P$ & OR & $95 \% \mathrm{Cl}$ & $P$ & OR & $95 \% \mathrm{Cl}$ & $P$ \\
\hline \multicolumn{10}{|l|}{ All bystander-witnessed OHCAs } \\
\hline Age (10-year increase) & 0.87 & 0.86 to 0.89 & $<0.001$ & 0.78 & 0.76 to 0.79 & $<0.001$ & 0.96 & 0.95 to 0.98 & $<0.001$ \\
\hline \multicolumn{10}{|l|}{ Sex } \\
\hline Male & Ref. & & & Ref. & & & Ref. & & \\
\hline Female & 1.04 & 0.99 to 1.10 & 0.109 & 0.93 & 0.84 to 1.01 & 0.094 & 1.12 & 1.04 to 1.21 & 0.004 \\
\hline Call to EMS response (minutes) & 0.90 & 0.89 to 0.91 & $<0.001$ & 0.87 & 0.86 to 0.89 & $<0.001$ & 0.93 & 0.92 to 0.94 & $<0.001$ \\
\hline \multicolumn{10}{|l|}{ Causes of arrest } \\
\hline Noncardiac origin & Ref. & & & Ref. & & & Ref. & & \\
\hline Cardiac origin with initial non-VF & 0.65 & 0.62 to 0.69 & $<0.001$ & 1.12 & 1.00 to 1.25 & 0.050 & 0.54 & 0.49 to 0.59 & $<0.001$ \\
\hline Cardiac origin with initial VF & 3.57 & 3.37 to 3.79 & $<0.001$ & 6.41 & 5.82 to 7.07 & $<0.001$ & 1.66 & 1.51 to 1.82 & $<0.001$ \\
\hline \multicolumn{10}{|l|}{ Combination of BCPR and ACLS } \\
\hline ACLS by ELSTs without BCPR & Ref. & & & Ref. & & & Ref. & & \\
\hline ACLS by ELSTs with BCPR & 1.51 & 1.43 to 1.59 & $<0.001$ & 2.23 & 2.05 to 2.42 & $<0.001$ & 1.09 & 1.02 to 1.18 & 0.018 \\
\hline ACLS by physicians without $B C P R$ & 1.63 & 1.39 to 1.92 & $<0.001$ & 1.18 & 0.86 to 1.61 & 0.317 & 1.87 & 1.52 to 2.32 & $<0.001$ \\
\hline ACLS by physicians with $B C P R$ & 2.17 & 1.89 to 2.49 & $<0.001$ & 2.80 & 2.28 to 3.43 & $<0.001$ & 1.45 & 1.17 to 1.80 & 0.001 \\
\hline \multicolumn{10}{|c|}{ Bystander-witnessed OHCAs with initial VF of cardiac origin } \\
\hline Age (10-year increase) & 0.85 & 0.83 to 0.86 & $<0.001$ & 0.79 & 0.77 to 0.81 & $<0.001$ & 0.99 & 0.95 to 1.03 & 0.669 \\
\hline \multicolumn{10}{|l|}{ Sex } \\
\hline Male & Ref. & & & Ref. & & & Ref. & & \\
\hline Female & 1.17 & 1.07 to 1.27 & $<0.001$ & 1.09 & 0.97 to 1.22 & 0.137 & 1.14 & 0.99 to 1.32 & 0.076 \\
\hline Call to EMS response (minutes) & 0.90 & 0.89 to 0.91 & $<0.001$ & 0.90 & 0.88 to 0.92 & $<0.001$ & 0.93 & 0.91 to 0.95 & $<0.001$ \\
\hline \multicolumn{10}{|l|}{ Combination of BCPR and ACLS } \\
\hline ACLS by ELSTs without BCPR & Ref. & & & Ref. & & & Ref. & & \\
\hline ACLS by ELSTs with BCPR & 1.18 & 1.09 to 1.26 & $<0.001$ & 1.30 & 1.18 to 1.43 & $<0.001$ & 1.00 & 0.88 to 1.14 & 0.993 \\
\hline ACLS by physicians without BCPR & 1.87 & 1.49 to 2.34 & $<0.001$ & 1.60 & 1.20 to 2.14 & 0.002 & 1.56 & 1.09 to 2.24 & 0.016 \\
\hline ACLS by physicians with $B C P R$ & 2.10 & 1.72 to 2.56 & $<0.001$ & 2.06 & 1.62 to 2.63 & $<0.001$ & 1.28 & 0.90 to 1.83 & 0.167 \\
\hline
\end{tabular}

Logistic regression analyses for 1-month outcomes for all the bystander-witnessed out-of-hospital cardiac arrests (OHCAs) $(n=95,072)$ and those with initial ventricular fibrillation (VF) of cardiac origin $(n=11,970)$. ACLS, advanced cardiac life support; BCPR, bystander-initiated cardiopulmonary resuscitation; Cl, confidence interval; ELST, emergency life-saving technician; EMS, emergency medical service; OR, odds ratio; Ref., reference.

\section{Discussion}

Survival from OHCA remains poor in most countries [2-8]. Numerous studies have suggested that BCPR is the most fundamental factor for improving the survival of OHCA patients [3-6,9]. In the present study, BCPR significantly improved survival with good cerebral performance, and an independent effect of BCPR for OHCA patients was demonstrated.

One of the significant findings of the present study was the improvement of both the overall 1-month survival and good neurological performance at 1 month in patients with ACLS by physicians. A previous report showed that a physician on board an ACLS unit was not an independent factor for improved survival, but the study only included 539 OHCA patients in a limited area [13]. To the best of our knowledge, the present study is the first to demonstrate the survival-improving effects of physician-manned ACLS in a nationwide setting.
Physician-staffed ambulances are in use in many European nations $[9,13,21,22]$, while paramedics in the United States are permitted to provide highly advanced support partially because physician-manned ambulances are considered an inefficient use of physician resources [9]. In Japan, extending the physician-staffed ambulance system may be practically difficult because of the shortage of emergency physicians [17].

Another important finding of the present study was the confirmation of high survival with poor neurological outcomes of bystander-witnessed OHCA patients treated with ACLS by physicians without BCPR. ACLS by physicians can reinforce the effects of preceding $B C P R$. In other words, the combination of BCPR and ACLS by physicians is considered the best way to achieve a patient's comeback from collapse and subsequent well-being. In the cases without BCPR, however, the crucial delay in receiving first aid presumably caused many survivors to suffer irreparable 
Table 4 Baseline characteristics and 1-month outcomes of patients whose arrests witnessed by EMS providers

\begin{tabular}{|c|c|c|c|c|c|c|}
\hline & \multicolumn{2}{|c|}{ All $(n=23,127)$} & \multicolumn{2}{|c|}{ ACLS by ELSTs $(n=22,131)$} & \multicolumn{2}{|c|}{ ACLS by physicians $(n=996)$} \\
\hline & $\bar{n}$ & $\%$ & $n$ & $\%$ & $n$ & $\%$ \\
\hline Sex (males) & 14,434 & 62.4 & 13,797 & 62.3 & 637 & 64.0 \\
\hline Age (years) & $69.6 \pm 18.0$ & & $69.8 \pm 17.9$ & & $65.2 \pm 20.0$ & \\
\hline \multicolumn{7}{|l|}{ Causes of arrest } \\
\hline Cardiac origin & 12,024 & 52.0 & 11,503 & 52.0 & 521 & 52.3 \\
\hline Noncardiac origin & 11,103 & 48.0 & 10,628 & 48.0 & 475 & 47.7 \\
\hline \multicolumn{7}{|l|}{ Initial rhythm } \\
\hline Ventricular fibrillation & 1,918 & 8.3 & 1,818 & 8.2 & 100 & 10.0 \\
\hline Pulseless electrical activity & 8,424 & 36.4 & 8,092 & 36.6 & 332 & 33.3 \\
\hline Asystole & 4,471 & 19.3 & 4,325 & 19.5 & 146 & 14.7 \\
\hline Others & 8,314 & 35.9 & 7,896 & 35.7 & 418 & 42.0 \\
\hline Call to EMS response (minutes) & $6.9 \pm 4.3$ & & $6.9 \pm 4.2$ & & $6.9 \pm 5.3$ & \\
\hline \multicolumn{7}{|l|}{ Outcomes } \\
\hline 1-month survival & 2,642 & 11.4 & 2,493 & 11.3 & 149 & 15.0 \\
\hline \multicolumn{7}{|l|}{ CPC at 1 month } \\
\hline Good performance & 1,325 & 5.7 & 1,235 & 5.6 & 90 & 9.0 \\
\hline Moderate disability & 234 & 1.0 & 223 & 1.0 & 11 & 1.1 \\
\hline Severe cerebral disability & 312 & 1.3 & 295 & 1.3 & 17 & 1.7 \\
\hline Vegetative status or worse & 765 & 3.3 & 734 & 3.3 & 31 & 3.1 \\
\hline
\end{tabular}

Data presented as $n$ or mean \pm standard deviation. ACLS, advanced cardiac life support; CPC, cerebral performance category; ELST, emergency life-saving technician; EMS, emergency medical service.

brain damage. Life support by physicians without preceding BCPR may cause an increase in unfavorable, and sometimes desperate, consequences. Our eyes must be opened to the fact that more than $40 \%$ of 1 -month survivors among the bystander-witnessed OHCA patients were classified as vegetative status or de facto brain death. Great care should be taken of the fact that more than $50 \%$ of 1 month survivors among the bystander-witnessed OHCA patients who underwent ACLS by physicians without BCPR were of vegetative status or de facto brain death. These are the realities of EMS procedures for OHCA patients.
Of course, it is not the physician intervention that is detrimental, but the duration of no blood flow. Our study clearly shows that priority should be given to the enhancement of BCPR to improve the neurologically favorable outcomes of OHCA patients. Teaching on how to behave in emergency situations is a common public health problem worldwide. Training programs in the school curriculum could be the best way to train the whole population $[23,24]$. In Japan, CPR training is performed for millions of citizens each year, and new driver license applicants have recently been obliged to undergo CPR training programs at driving schools [14]. Nevertheless, our study revealed

Table 5 Logistic regression analyses for 1-month outcomes for OHCAs witnessed by EMS providers $(n=23,127)$

\begin{tabular}{|c|c|c|c|c|c|c|c|c|c|}
\hline & \multicolumn{3}{|c|}{ 1-month survival } & \multicolumn{3}{|c|}{$\begin{array}{l}\text { Good performance at } 1 \\
\text { month }\end{array}$} & \multicolumn{3}{|c|}{$\begin{array}{l}\text { Vegetative status or de facto brain death at } \\
\qquad 1 \text { month }\end{array}$} \\
\hline & OR & $95 \% \mathrm{Cl}$ & $P$ & OR & $95 \% \mathrm{Cl}$ & $P$ & OR & $95 \% \mathrm{Cl}$ & $P$ \\
\hline Age (10-year increase) & 0.89 & 0.87 to 0.91 & $<0.001$ & 0.80 & 0.78 to 0.83 & $<0.001$ & 0.97 & 0.93 to 1.01 & 0.119 \\
\hline \multicolumn{10}{|l|}{ Sex } \\
\hline Male & Ref. & & & Ref. & & & Ref. & & \\
\hline Female & 1.02 & 0.94 to 1.12 & 0.617 & 0.90 & 0.79 to 1.02 & 0.097 & 1.18 & 1.02 to 1.37 & 0.028 \\
\hline \multicolumn{10}{|l|}{ Causes of arrest } \\
\hline Noncardiac origin & Ref. & & & Ref. & & & Ref. & & \\
\hline Cardiac origin with initial non-VF & 1.58 & 1.43 to 1.73 & $<0.001$ & 3.00 & 2.58 to 3.49 & $<0.001$ & 0.93 & 0.80 to 1.09 & 0.360 \\
\hline Cardiac origin with initial VF & 7.58 & 6.68 to 8.59 & $<0.001$ & 17.82 & 15.07 to 21.07 & $<0.001$ & 1.36 & 1.04 to 1.77 & 0.024 \\
\hline \multicolumn{10}{|l|}{ Advanced cardiac life support } \\
\hline By ELSTs & Ref. & & & Ref. & & & Ref. & & \\
\hline By physicians & 1.27 & 1.05 to 1.53 & 0.013 & 1.47 & 1.16 to 1.87 & 0.002 & 0.92 & 0.64 to 1.32 & 0.646 \\
\hline
\end{tabular}

$\mathrm{Cl}$, confidence interval; ELST, emergency life-saving technician; EMS, emergency medical service; OHCA, out-of-hospital cardiac arrest; OR, odds ratio; Ref., reference; VF, ventricular fibrillation. 
that BCPR only occurred in $42 \%$ of bystander-witnessed OHCA cases in Japan. While this figure is relatively high compared with many countries $[2,25]$, there is much room for improvement. Efforts should be made to improve the quantity and quality of BCPR. Ideally, ACLS by physicians should be linked with preceding BCPR.

Several limitations of the present study should be acknowledged. A randomized trial is not feasible for this type of study owing to ethical and informed consent issues. Furthermore, a large-scale randomized trial looking at physician EMS versus nonphysician EMS is very challenging to perform. Although the groups were large, the present study was based on a nonrandomized observational study and thus jeopardized by several potential biases. First, and most importantly, prehospital physician EMS was only available in limited geographical areas around specific emergency medical centers. Although our data lacked information on the hospitals receiving the patients, it appears likely that most patients in the physician EMS groups (Group C and Group D) were brought to the specific hospitals to which the physicians on board were affiliated. It also seems likely that a relationship between physician EMS and outcomes could partly reflect differences in post-return of spontaneous circulation treatments available at receiving hospitals; including therapeutic hypothermia [26-28], percutaneous coronary intervention, and a focus on goal-directed treatment for the reperfusion period [28]. These treatments are only available at some centers, potentially influencing outcomes. We were unable to adjust for this factor because we had no information on what treatments were performed at the receiving hospitals. Second, similar to all registry-based surveys, the validity and integrity of the data were potential limitations, although they were minimized by the large sample size collected with the population-based design. Finally, long-term outcomes such as the rate of discharge from hospital or 1-year survival could not be assessed.

\section{Conclusions}

BCPR significantly improved the survival of OHCA patients with good cerebral performance. The combination of BCPR and ACLS by physicians was the best way to improve the outcomes. ACLS by physicians without preceding $B C P R$, however, increased the incidence of neurologically unfavorable outcomes. Priority should be given to the enhancement of BCPR, and ACLS by physicians should ideally be linked with preceding BCPR.

\section{Key messages}

- Among 95,072 patients with bystander-witnessed OHCA, 7,722 (8.1\%) patients were alive at 1 month, including 2,754 (2.9\%) with good performance and 3,171 (3.3\%) with vegetative status or worse.
- More than $40 \%$ of 1 -month survivors were classified as vegetative status or de facto brain death.

- The combination of BCPR and ACLS by physicians was the best way to improve outcomes.

- Life support by physicians without preceding BCPR increased the occurrence of vegetative status or worse.

\section{Abbreviations}

ACLS: advanced cardiac life support; BCPR: bystander-initiated cardiopulmonary resuscitation; CPC: cerebral performance category; CPR: cardiopulmonary resuscitation; ELST: emergency life-saving technician; EMS: emergency medical service; FDMA: Fire and Disaster Management Agency of Japan; OHCA: out-of-hospital cardiac arrest; OR: odds ratio; VF: ventricular fibrillation.

\section{Acknowledgements}

The authors thank the Fire and Disaster Management Agency of Japan for offering the data.

\section{Author details}

${ }^{1}$ Department of Health Management and Policy, Graduate School of Medicine, The University of Tokyo, 7-3-1 Hongo, Bunkyo-ku, Tokyo 113-8655, Japan. ${ }^{2}$ Foundation for Ambulance Service Development, Emergency LifeSaving Technique Academy of Tokyo, 4-5 Minami-osawa, Hachioji, Tokyo 192-0364, Japan. '3epartment of Public Health, Health Management and Policy, Nara Medical University School of Medicine, 840 Shijocho, Kashihara, Nara 634-8521, Japan. ${ }^{4}$ Department of Planning, Information and Management, The University of Tokyo Hospital, 7-3-1 Hongo, Bunkyo-ku, Tokyo 113-8655, Japan.

\section{Authors' contributions}

$H Y, H H, S T, M A, T O, S K$ and TI participated in the idea formation, study design, data analyses, interpretation of results and writing of the report. All the authors read and approved the final manuscript.

\section{Competing interests}

The authors declare that they have no competing interests.

Received: 2 April 2010 Revised: 1 June 2010

Accepted: 4 November 2010 Published: 4 November 2010

\section{References}

1. Pantridge JF, Geddes JS: A mobile intensive-care unit in the management of myocardial infarction. Lancet 1967, 2:271-273.

2. Stiell IG, Wells GA, Field B, Spaite DW, Nesbitt LP, De Maio VJ, Nichol G, Cousineau D, Blackburn J, Munkley D, Luinstra-Toohey L, Campeau T, Dagnone E, Lyver M, Ontario Prehospital Advanced Life Support Study Group: Advanced cardiac life support in out-of-hospital cardiac arrest. N Engl J Med 2004, 351:647-656.

3. Iwami T, Nichol G, Hiraide A, Hayashi Y, Nishiuchi T, Kajino K, Morita H, Yukioka $H$, Ikeuchi $H$, Sugimoto $H$, Nonogi $H$, Kawamura T: Continuous improvements in 'chain of survival' increased survival after out-ofhospital cardiac arrests: a large-scale population-based study. Circulation 2009, 119:728-734.

4. Kim C, Fahrenbruch CE, Cobb LA, Eisenberg MS: Out-of-hospital cardiac arrest in men and women. Circulation 2001, 104:2699-2703.

5. Arrich J, Zeiner A, Sterz F, Janata A, Uray T, Richling N, Behringer W, Herkner $\mathrm{H}$ : Factors associated with a change in functional outcome between one month and six months after cardiac arrest: a retrospective cohort study. Resuscitation 2009, 80:876-880.

6. Peberdy MA, Silver A, Ornato JP: Effect of caregiver gender, age, and feedback prompts on chest compression rate and depth. Resuscitation 2009, 80:1169-1174.

7. Rea TD, Eisenberg MS, Becker $\sqcup$, Murray JA, Hearne T: Temporal trends in sudden cardiac arrest: a 25-year emergency medical services perspective. Circulation 2003, 107:2780-2785. 
8. Wachelder EM, Moulaert VR, van Heugten C, Verbunt JA, Bekkers SC, Wade DT: Life after survival: long-term daily functioning and quality of life after an out-of-hospital cardiac arrest. Resuscitation 2009, 80:517-522.

9. Cummins RO, Ornato JP, Thies WH, Pepe PE: Improving survival from sudden cardiac arrest: The 'Chain of Survival' concept. Circulation 1991, 83:1832-1847.

10. Kvaloy JT, Skogvoll E, Eftestol T, Gundersen K, Kramer-Johansen J, Olasveengen TM, Steen PA: Which factors influence spontaneous state transitions during resuscitation? Resuscitation 2009, 80:863-869.

11. Kitamura T, Iwami T, Kawamura T, Nagao K, Tanaka H, Hiraide A: Nationwide public-access defibrillation in Japan. N Engl J Med 2010, 362:994-1004

12. Olasveengen TM, Lund-Kordahl I, Steen PA, Sunde K: Out-of hospital advanced life support with or without a physician: effects on quality of CPR and outcome. Resuscitation 2009, 80:1248-1252.

13. Estner HL, Gunzel C, Ndrepepa G, William F, Blaumeiser D, Rupprecht B, Hessling G, Deisenhofer I, Weber MA, Wilheim K, Schmitt C, Schomig A: Outcome after out-of-hospital cardiac arrest in a physician-staffed emergency medical system according to the Utstein style. Am Heart J 2007, 153:792-799.

14. Tanigawa K, Tanaka K: Emergency medical service systems in Japan: past, present, and future. Resuscitation 2006, 69:365-370.

15. ECC Committee, Subcommittees and Task Forces of the American Heart Association: 2005 American Heart Association guidelines for cardiopulmonary resuscitation and emergency cardiovascular care. Circulation 2005, 112:IV1-IV203.

16. International Liaison Committee on Resuscitation: 2005 international consensus on cardiopulmonary resuscitation and emergency cardiovascular care science with treatment recommendations. Resuscitation 2005, 67:181-314.

17. Ohshige K, Shimazaki S, Hirasawa H, Nakamura M, Kin H, Fujii C, Okuchi K, Yamamoto Y, Akashi K, Takeda J, Hanyuda T, Tochikubo O: Evaluation of out-of-hospital cardiopulmonary resuscitation with resuscitative drugs: a prospective comparative study in Japan. Resuscitation 2005, 66:53-61.

18. Kai T: Development of prehospital emergency medical system: doctor car system [in Japanese]. Kyukyu Igaku 2009, 33:503-506.

19. Health Policy Bureau, Ministry of Health, Labour Welfare: The List of Emergency and Critical Care Centers in Japan. [http://www.wam.go.jp/ wamappl/bb11GS20.nsf/0/8f7f4a9f85da3368492575ef00058d35/\$FILE/ 20090710_1sankou7_3.pdf].

20. Jacobs I, Nadkarni V, Bahr J, Berg RA, Billi JE, Bossaert L, Cassan P, Coovadia A, D'Este K, Finn J, Halperin H, Handley A, Herlitz J, Hickey R, Idris A, Kloeck W, Larkin GL, Mancini ME, Mason P, Mears G, Monsieurs K, Montgomery W, Morley P, Nichol G, Nolan J, Okada K, Perlman J, Shuster M, Steen PA, Sterz F, et al: Cardiac arrest and cardiopulmonary resuscitation outcome reports: update and simplification of the Utstein templates for resuscitation registries: a statement for healthcare professionals from a task force of the International Liaison Committee on Resuscitation. Circulation 2004, 110:3385-3397.

21. Nikkanen HE, Pouges C, Jacobs LM: Emergency medicine in France. Ann Emerg Med 1998, 31:116-120.

22. Kruger AJ, Skogvoll E, Castren M, Kurola J, Lossius HM, The ScanDoc Phase 1a Study Group: Scandinavian pre-hospital physician-manned emergency medical services - same concept across borders? Resuscitation 2010, 81:427-433.

23. Connolly M, Toner $\mathrm{P}$, Connolly D, McCluskey DR: The 'ABC for life' programme teaching basic life support in schools. Resuscitation 2007, 72:270-279.

24. Fleischhackl R, Nuernberger A, Sterz F, Schoenberg C, Urso T, Habart T, Mittlboeck M, Chandra-Strobos N: School children sufficiently apply life supporting first aid: a prospective investigation. Crit Care 2009, 13:R127.

25. Lopez-Herce J, Alvarez AC: Bystander CPR for paediatric out-of-hospital cardiac arrest. Lancet 2010, 375:1321-1322.

26. The Hypothermia after Cardiac Arrest Study Group: Mild therapeutic hypothermia to improve the neurologic outcome after cardiac arrest. $N$ Engl J Med 2002, 346:549-556.

27. Bernard SA, Gray TW, Buist MD, Jones BM, Silvester W, Gutteridge G, Smith K: Treatment of comatose survivors of out-of-hospital cardiac arrest with induced hypothermia. N Engl J Med 2002, 346:557-563.
28. Sunde K, Pytte M, Jacobsen D, Mangschau A, Jensen LP, Smedsrud C, Draegni T, Steen PA: Implementation of a standardised treatment protocol for post resuscitation care after out-of-hospital cardiac arrest. Resuscitation 2007, 73:29-39.

doi:10.1186/cc9319

Cite this article as: Yasunaga et al:: Collaborative effects of bystanderinitiated cardiopulmonary resuscitation and prehospital advanced cardiac life support by physicians on survival of out-of-hospital cardiac arrest: a nationwide population-based observational study. Critical Care 2010 14:R199.

\section{Submit your next manuscript to BioMed Central and take full advantage of:}

- Convenient online submission

- Thorough peer review

- No space constraints or color figure charges

- Immediate publication on acceptance

- Inclusion in PubMed, CAS, Scopus and Google Scholar

- Research which is freely available for redistribution

Submit your manuscript at www.biomedcentral.com/submit
Ciomed Central 